Classification

Physics Abstracts

$81.15 \mathrm{~L}$

\title{
L.P.E. growth rate in Ga-As-Ge and Ga-As-Sn systems
}

\author{
D. Dutartre and M. Gavand
}

Laboratoire de Physique de la Matière (*), Institut National des Sciences Appliquées de Lyon, 20, avenue Albert Einstein, 69621 Villeurbanne Cedex, France

(Reçu le 29 juillet 1983, révisé le 10 octobre, accepté le 13 octobre 1983)

\begin{abstract}
Résumé. - L'obtention de dopages élevés dans les couches épitaxiales de GaAs réalisées en phase liquide nécessite d'importantes quantités de $\mathrm{Ge}$ ou de $\mathrm{Sn}$ dans le bain. L'influence de ces éléments sur la cinétique de croissance du solide est déterminée à $1073 \mathrm{~K}$ pour $0 \leqslant x_{\mathrm{Ge}}^{\mathrm{L}} \leqslant 0,55$ et pour $0 \leqslant x_{\mathrm{Sn}}^{\mathrm{L}} \leqslant 0,8$. On montre que l'épaisseur déposée n'est pas modifiée par la présence de Ge alors qu'elle est fortement augmentée par de grandes concentrations de $\mathrm{Sn}$. L'interprétation de ces résultats par un modèle de croissance limitée par la diffusion conduit à des estimations des coefficients de diffusion du soluté As dans les alliages liquides Ga-Ge et Ga-Sn. Les valeurs trouvées augmentent avec la fraction de dopant mais restent du même ordre de grandeur que celle dans le gallium pur.

Abstract. - High doping levels in GaAs grown by L.P.E. necessitate large amounts of Ge or Sn in the melt. The influence of these elements on the growth rate of $\mathrm{GaAs}$ is studied. The experiments were carried out at $1073 \mathrm{~K}$ over wide ranges : $x_{\mathrm{Ge}}^{\mathrm{L}}$ up to 0.55 and $x_{\mathrm{Sn}}^{\mathrm{L}}$ up to 0.8 . It was shown that the layer thickness is not modified by Ge whereas it is greatly increased by large fractions of $\mathrm{Sn}$. These results are then analysed on the basis of a diffusion limited growth model. The estimated values of As diffusion in Ga-Ge and Ga-Sn melts increase with $x_{\text {dopant }}^{\mathrm{L}}$, but are about the same value as in pure $\mathrm{Ga}$.
\end{abstract}

\section{Introduction.}

Up to now GaAs has been one of the most extensively used III-V compounds for electronic devices prepared by liquid phase epitaxy (L.P.E.). To improve the performance of these devices it is necessary, among other problems, to have good control of layer thicknesses that can be achieved by using the horizontal slidingboat technique. Numerous workers [1-7] have analysed the growth rate of GaAs from binary melts $\mathrm{Ga}+$ As. When considering high doping levels and using dopants with small distribution coefficients, the melt composition can be far from the binary III-V boundary and the growth rate is generally modified. Thus, we must consider the growth in the ternary system, Ga-As-dopant, what has not been done before, to our knowledge. Ga-As-Ge and Ga-As-Sn are such systems. A low partial vapour pressure and a low diffusion coefficient in the solid make $\mathrm{Ge}$ and $\mathrm{Sn}$ ideal doping elements. This study provides measurements of L.P.E. growth rate of GaAs in the GaAs-Sn systems. These experimental data are then compared with results of calculations based on a diffusion limited growth model.

\section{Theoretical approach.}

2.1 GROWTH FROM A BINARY MELT. - The growth rate of $\mathrm{GaAs}$ in the L.P.E. technique has been extensively studied. At the present time, it is practically impossible to observe in situ the limiting phenomenon which acts during epitaxial growth from high temperature solution. Hence the growth mechanisms can only be determined indirectly. So, under the generally used growth conditions the dependence of layer thickness on super-saturation, cooling rate, and time, are quantitatively consistent with calculations based on the diffusion limited growth model. To be easily solved this model requires a few commonly accepted assumptions; these latter are used in this study and they are as follows : very fast interface kinetics (liquid-solid), no convection, constant diffusion coefficient (during the growth procedure), no parasitic nucleation, and semi-infinite melts.

Only a thin layer is grown from a large volume of dilute solution, so the one dimensional diffusion equation can be considered as stationary ; then :

$$
D_{\mathrm{As}} \frac{\partial^{2} C_{\mathrm{As}}^{\mathrm{L}}(x, t)}{\partial x^{2}}=\frac{\partial C_{\mathrm{As}}^{\mathrm{L}}(x, t)}{\partial t}
$$

(*) LA-CNRS no 358. 


$$
D_{\mathrm{As}} \frac{\partial C_{\mathrm{As}}^{\mathrm{L}}(0, t)}{\partial x}=v(t)\left(C_{\mathrm{As}}^{\mathrm{s}}(0, t)-C_{\mathrm{As}}^{\mathrm{L}}(0, t)\right)
$$

and

$$
d(t)=\int_{0}^{t} v(t) \mathrm{d} t
$$

$C_{\mathrm{As}}^{\mathrm{L}}$ and $C_{\mathrm{As}}^{\mathrm{S}}$ are the concentrations of As in the liquid phase and in crystalline GaAs respectively, $D_{\mathrm{As}}$ the As diffusion coefficient in liquid $\mathrm{Ga}$, and $v(t)$ and $d(t)$ the growth rate and the thickness of the epitaxial layer.

Respecting the given assumptions, these equations have been previously solved for boundary conditions which correspond to different cooling programs used in L.P.E. : step-cooling, equilibrium-cooling and supercooling. Temperature changes $\Delta T$ are taken to be sufficiently small so that a linear approximation to the phase diagram is valid, so for the supercooling case, the boundary equations are writen as :

$$
\begin{aligned}
C_{\mathrm{As}}^{\mathrm{L}}(0, t) & =C_{\mathrm{As}}^{\mathrm{L}}(x, 0)-\frac{\Delta T}{m_{\mathrm{As}}}-\frac{a t}{m_{\mathrm{As}}} \\
\lim C_{\mathrm{As}}^{\mathrm{L}}(x, t) & =C_{\mathrm{As}}^{\mathrm{L}}(x, 0) \quad(\text { whatever } t \text { is) }
\end{aligned}
$$

where $m_{\mathrm{As}}$ is the slope of the liquidus $\left(\mathrm{d} T / \mathrm{d} C_{\mathrm{As}}^{\mathrm{L}}\right), a$ the cooling rate $(-\mathrm{d} T / \mathrm{d} t)$ and $\Delta T$ the initial super-

The solution becomes :

$$
d(t)=\frac{2}{m_{\mathrm{As}} C_{\mathrm{As}}^{\mathrm{S}}} \sqrt{\frac{D_{\mathrm{As}}}{\pi}}\left(\Delta T t^{1 / 2}+\frac{2}{3} a t^{3 / 2}\right) .
$$

2.2 GROWTH FROM A TERNARY MELT. - No theoretical or experimental information is available in the literature about the growth of GaAs from a Ga-Asdopant melt. This study assumes the growth to be limited by liquid diffusion as in the earlier case. Moreover, the diffusion equations will be solved using the same assumptions. As the change of molar volume between the $\mathrm{Ga}^{\mathrm{L}}+\mathrm{As}^{\mathrm{L}}$ melt and the GaAs solid is generally not taken into account, here this change between the melt and the solid will be neglected. The deposited layer thickness will be calculated by integration of the As flux through the liquid-solid interface. This flux will be dependent on the diffusion coefficient, $D_{A s}$, and on the boundary equations. $D_{\text {As }}$ can be a function of the melt composition but it will be considered as constant during the growth procedure (the temperature and composition changes are not large). To formulate the boundary equations, the As composition variation at the liquid solid interface must be calculated.

Figure 1 shows a schematic isotherm of the Ga-Asdopant phase diagram. In a plot of the As mole fraction versus the dopant mole fraction, two isotherm

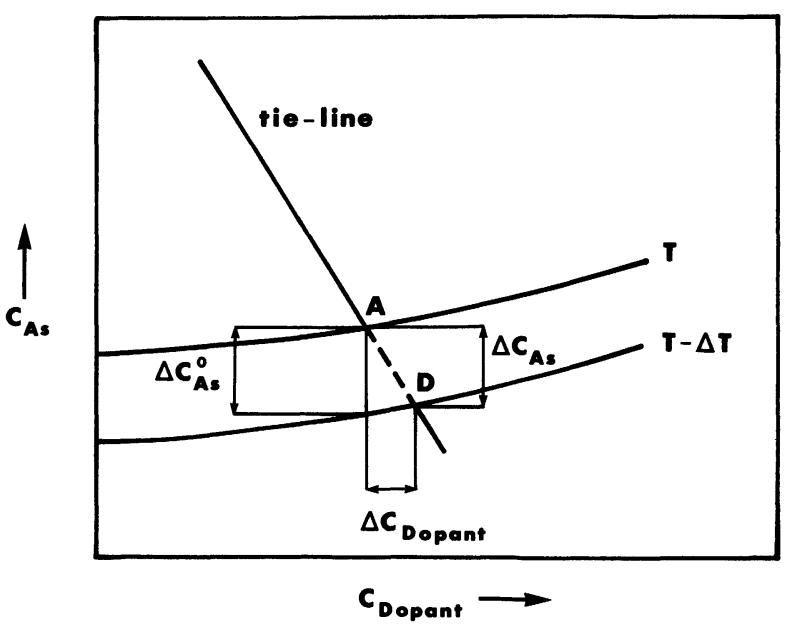

Fig. 1. - The Ga-rich corner of the schematic Ga-Asdopant phase diagram.

liquidus $T$ and $T-\Delta T$ have been drawn. If the initial composition $C^{\mathrm{L}}(x, 0)$ is represented by $A$, then when cooling the system by $\Delta T, C^{\mathrm{L}}(0, t)$ comes to the lower isotherm.

To locate the point $D$ which represents $C^{\mathrm{L}}(0, t)$ on this liquidus, the initial diffusion of the various components must be studied.

For each component :

$$
\begin{gathered}
D_{i} \frac{i_{i} x, t}{\partial x^{2}}=\frac{i x, t}{\partial t} \\
D_{i} \frac{\partial C_{i}^{\mathrm{L}}(0, t)}{\partial x}=v(t)\left(C_{i}^{\mathrm{S}}(0, t)-C_{i}^{\mathrm{L}}(0, t)\right) \\
d(t)=\int_{0}^{t} v(t) \mathrm{d} t
\end{gathered}
$$

where $D_{i}$ is the effective diffusion coefficient

According to Carslaw [8], $\Delta C_{i}^{\mathrm{L}}(0, t)$, defined as $C_{i}^{\mathrm{L}}(0, t)-C_{i}^{\mathrm{L}}(x, 0)$, can be expressed as follows :

$$
\Delta C_{i}^{\mathrm{L}}(0, t)=\left(\pi D_{i}\right)^{-1 / 2} \int_{0}^{t} F_{i}(0, t-\tau) \tau^{-1 / 2} \mathrm{~d} \tau
$$

where $F_{i}(0, t-\tau)$ is the flux of the $i$ species at the abscisse 0 and at the time $t-\tau$

$$
F_{i}(0, t-\tau)=\left(C_{i}^{\mathrm{S}}-C_{i}^{\mathbf{L}}\right) v(t-\tau) .
$$

In our case, during the growth procedure, the solid and liquid compositions are constant or roughly constant, so $C_{i}^{\mathrm{S}}-C_{i}^{\mathrm{L}}$ can be taken as constant and :

$\Delta C_{i}^{\mathrm{L}}(0, t)=\left(\pi D_{i}\right)^{-1 / 2}\left(C_{i}^{\mathrm{S}}-C_{i}^{\mathrm{L}}\right) \int_{0}^{t} v(t-\tau) \tau^{-1 / 2} \mathrm{~d} \tau$

where the integral is the same for all components. 
So, we have for example :

$$
\begin{aligned}
& \frac{\Delta C_{\mathrm{As}}^{\mathrm{L}}(0, t)}{\Delta C_{\mathrm{Ge}}^{\mathrm{L}}(0, t)}=\sqrt{\frac{D_{\mathrm{Ge}}}{D_{\mathrm{As}}}} \frac{C_{\mathrm{As}}^{\mathrm{s}}-C_{\mathrm{As}}^{\mathrm{L}}}{-C_{\mathrm{Ge}}^{\mathrm{L}}} \simeq \\
& \simeq \sqrt{\frac{D_{\mathrm{Ge}}}{D_{\mathrm{As}}}} \frac{x_{\mathrm{As}}^{\mathrm{L}}-0.5}{x_{\mathrm{Ge}}^{\mathrm{L}}} .
\end{aligned}
$$

From equation 6, we get the slope of the crystallization path which is found rectilinear. Furthermore, for equal diffusion coefficients, this crystallization path is in the tie-line extension.

In the liquid metals, the diffusion coefficients are fairly equal and thus the actual path $A D$ must be close to the tie-line extension. In the ternary systems of Ga-As-dopant type the As solubility is not largely dependent on the dopant atom fraction. With these two remarks, we can conclude that the As slope $m_{\text {As }}$ on the liquidus area will not depend on the exact $A D$ orientation. This appears in :

$$
\frac{1}{m_{\mathrm{As}}}=\frac{1}{m_{\mathrm{As}}^{0}}+m \frac{1}{m_{\mathrm{dopant}}}
$$

which is easily obtained with the aid of figure 1 with

$$
\begin{aligned}
& m_{\mathrm{As}}^{0}=\left.\frac{\partial T}{\partial C_{\mathrm{As}}^{\mathrm{L}}}\right|_{C_{\text {dopant }}} \\
& m_{i}=\left.\frac{\partial T}{\partial C_{i}^{\mathrm{L}}}\right|_{A D} \\
& m=\left.\frac{\partial C_{\mathrm{As}}^{\mathrm{L}}}{\partial C_{\mathrm{dopant}}^{\mathrm{L}}}\right|_{T}
\end{aligned}
$$

where $m$ has a very low value (see table I).

In this way, the growth rate calculations are carried out in the ternary system $\mathrm{Ga}-\mathrm{As}-\mathrm{Ge}$ and Ga-As-Sn using $m_{\mathrm{As}}$ along the tie-line. This can be a rather rough approximation in a ternary system where $m$ has a high value (III-III'-V type for example) $[9,10]$.

Finally, the diffusion and boundary equations for the dilute component As are identical with those of part 2.1. So the thickness of the deposited layer for the supercooling program is given by :

$$
d(t)=\frac{2}{m_{\mathrm{As}} C_{\mathrm{As}}^{\mathrm{S}}} \sqrt{\frac{D_{\mathrm{As}}}{\pi}}\left(\Delta T t^{1 / 2}+\frac{2}{3} a t^{3 / 2}\right)
$$

where $m_{\mathrm{As}}$ is the ternary liquidus slope and $D_{\mathrm{As}}$ the As diffusion coefficient in the Ga-dopant melt.

\section{Experimental.}

3.1 EXPERIMENTAL PROCEDURE. - The growth of epitaxial layers onto (100) oriented GaAs substrates was carried out in a L.P.E. reactor using the horizontal sliding-boat technique [11]. After baking $\mathrm{Ga}$ in a graphite boat $(3 \mathrm{~h}$ at $1073 \mathrm{~K})$, under flowing Pddiffused $\mathrm{H}_{2}$ gas, $\mathrm{GaAs}$ and the dopant were added to the $\mathrm{Ga}$. The source and seed wafers were all loaded on the same slide. Then the furnace was heating at $1073 \mathrm{~K}$, the source was brought into contact with melt, and the saturation condition was maintained for $2 \mathrm{~h}$. Finally, the source was removed, the cooling program was initiated, and the growth occurred when the seed was brought under the melt.

3.2 Growth Limitations. - We have observed that supercooling of more than 8 or $12 \mathrm{~K}$ induces a parasitic nucleation in the melt, which is supported by the study of Toyoda [5]. This is the first limitation phenomenon. Our melts have a thickness of about 6 to $8 \mathrm{~mm}$ and the diffusion coefficients are in the range of $10^{-4} \mathrm{~cm}^{2} \mathrm{~s}^{-1}$, so it requires a relaxation time of about one hour. For shorter times the influence of the upper boundary will be negligible. The use of a very small temperature slope and of a flat temperature profile leads to a minimum convection phenomenon. In the

Table I. - Systems Ga-As-Ge and Ga-As-Sn : $1073 \mathrm{~K}$ liquidus slopes defined as $M_{\mathrm{As}}^{0}=\partial T /\left.\partial x_{\mathrm{As}}\right|_{\boldsymbol{x}_{\mathrm{dopant}}}$ and $M_{\mathrm{As}}=\partial T /\left.\partial x_{\mathrm{As}}\right|_{A D}$.

\begin{tabular}{|c|c|c|c|c|c|c|}
\cline { 2 - 7 } \multicolumn{1}{c|}{} & \multicolumn{3}{c|}{ Ga-As-Ge system } & \multicolumn{3}{c|}{ Ga-As-Sn system } \\
\hline$x_{\text {dopant }}^{\mathrm{L}}$ & $M_{\text {As }}^{0}(\mathrm{~K})$ & $m$ & $M_{\text {As }}(\mathrm{K})$ & $M_{\text {As }}^{0}(\mathrm{~K})$ & $m$ & $M_{\text {As }}(\mathrm{K})$ \\
\hline 0.0 & 4124 & -0.0176 & 4124 & 4124 & 0.0184 & 4124 \\
0.1 & 4464 & -0.0126 & 4454 & 3914 & 0.0164 & 3927 \\
0.2 & 4705 & -0.0078 & 4693 & 3724 & 0.0152 & 3745 \\
0.3 & 4866 & -0.003 & 4859 & 3552 & 0.0148 & 3584 \\
0.4 & 4902 & +0.0028 & 4914 & 3361 & 0.017 & 3413 \\
0.5 & 4739 & +0.011 & 4794 & 3115 & 0.0234 & 3195 \\
0.55 & 4566 & +0.0172 & 4658 & 2963 & 0.0294 & 3058 \\
0.6 & 4329 & +0.0258 & 4484 & 2778 & 0.0392 & 2924 \\
0.7 & - & - & - & 2247 & 0.084 & 2538 \\
0.8 & - & - & - & 1246 & 0.351 & 2036 \\
\hline
\end{tabular}


same way, the horizontal L.P.E. method with « one phase " (see part 3.1) does not induce convection by concentration gradient.

Finally, the supercooling technique has been chosen with an initial supercooling of $2 \mathrm{~K}$, a cooling rate of $0.2 \mathrm{~K} \mathrm{~min}^{-1}$ and a growth time of $20 \mathrm{~min}$.

3.3 ThiCKNeSS MEASUREMENTS. - Layer thicknesses were measured by means of scanning electron microscopy (SEM) and of Nomarski interferential microscopy on stained cleavages. The samples were stained with the $A+B$ solution [12] for a few seconds at room temperature. The measurements errors and the distribution of growth thicknesses have been taken into consideration in the uncertainty bars represented on the figures. Moreover, the surface of layers were always smooth and free of melt droplets; for example, the figure 2 shows a cleavage of a layer grown from a melt with a Ge fraction of 0.55 .

\section{Results.}

4. 1 EXPERIMENTAL RESULTS. - Epitaxial layers have been grown along the $1073 \mathrm{~K}$ isotherm liquidus in the $\mathrm{Ga}$ side of the ternary system Ga-As-dopant using the supercooling method described in part 3.2. Each experimental datum was obtained from several measurements on the same sample.

For the Ga-As-Ge system we have studied the composition range $0 \leqslant x_{\mathrm{Ge}} \leqslant 0.55$. The upper boundary originates from the eutectic valley, $x_{\mathrm{Ge}} \simeq 0.64$, and from problems involved in the removal of the

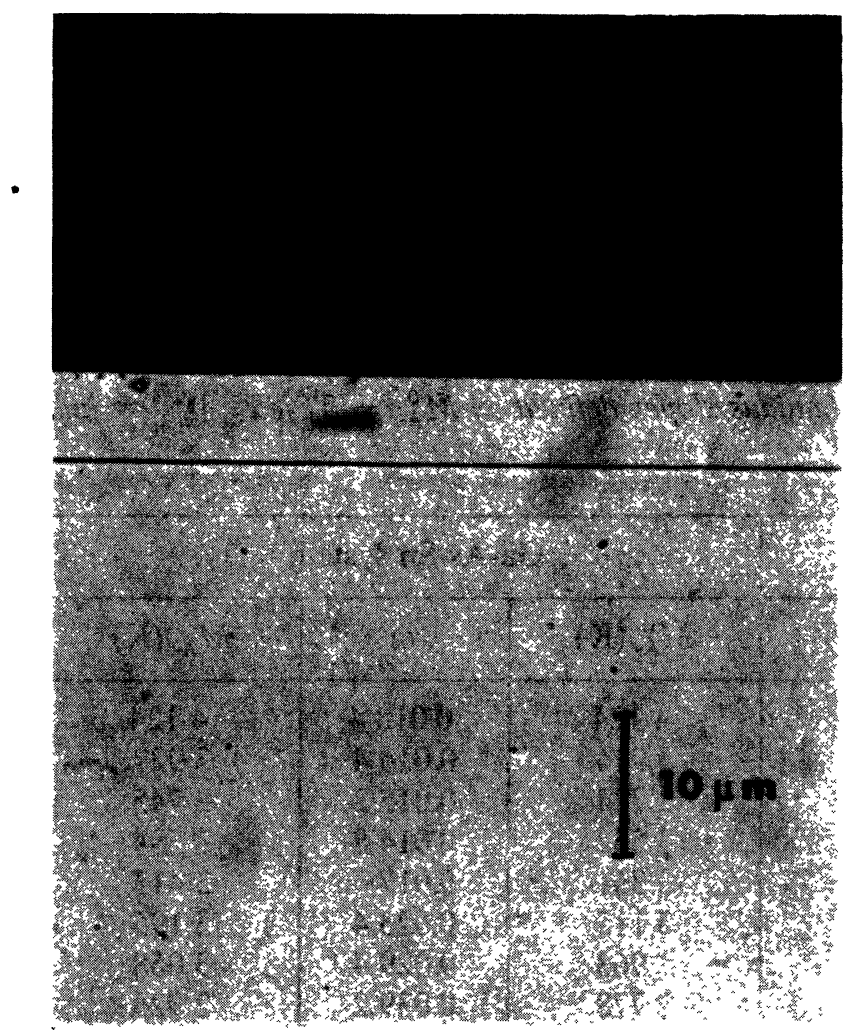

Fig. 2. - Nomarski micrograph : GaAs layer grown from Ge-rich solution $\left(x_{\mathrm{Ge}}=0.55\right)$ at $1073 \mathrm{~K}$. melt from the boat at room temperature. The results are shown in the figure 3. Finally, large amounts of Ge in the melt have a very small influence on the thickness of the deposited layer.

For the Ga-As-Sn system we have studied the composition range $0 \leqslant x_{\text {Sn }} \leqslant 0.8$. The experimental data versus $\mathrm{Sn}$ composition are given in figure 4 . In contrast to $\mathrm{Ge}$, the presence of large amounts of $\mathrm{Sn}$ has a great effect on the growth rate of GaAs, so the thickness of the deposited layers varies from 6 to $16 \mu \mathrm{m}$.

4.2 Calculations and discussion. - As shown in part 2.2, the presence of large amounts of a doping element in the melt act by the two factors $m_{\mathrm{As}}$ and $D_{\mathrm{As}}$. The liquidus slope $m_{\mathrm{As}}$ is generally modified by addition of dopant and the diffusion coefficient of the solute As can be dependent on the composition of the solvent Ga-dopant. In the first instance, it is necessary to obtain $m_{\text {As }}$ from phase diagram data.

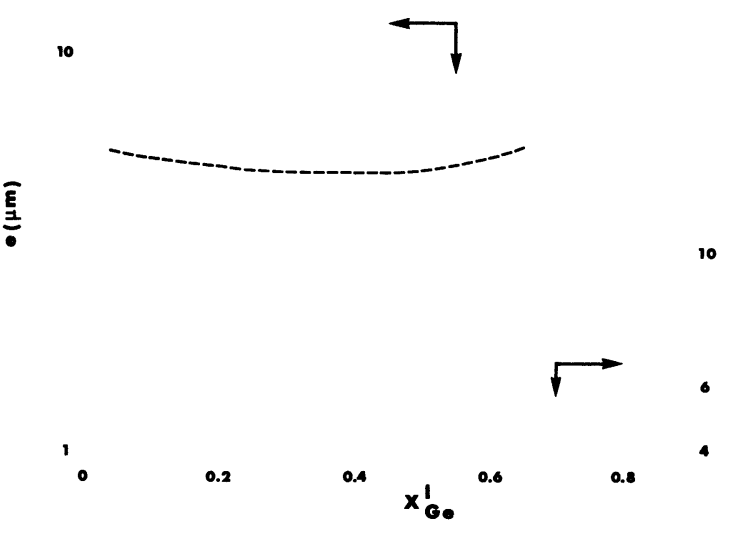

Fig. 3. - Experimental and calculated thickness of GaAs layer (upper curve) and estimated values of $D_{\mathrm{As}}$ in $\mathrm{Ga}-\mathrm{Ge}$ liquid alloy (lower curve).

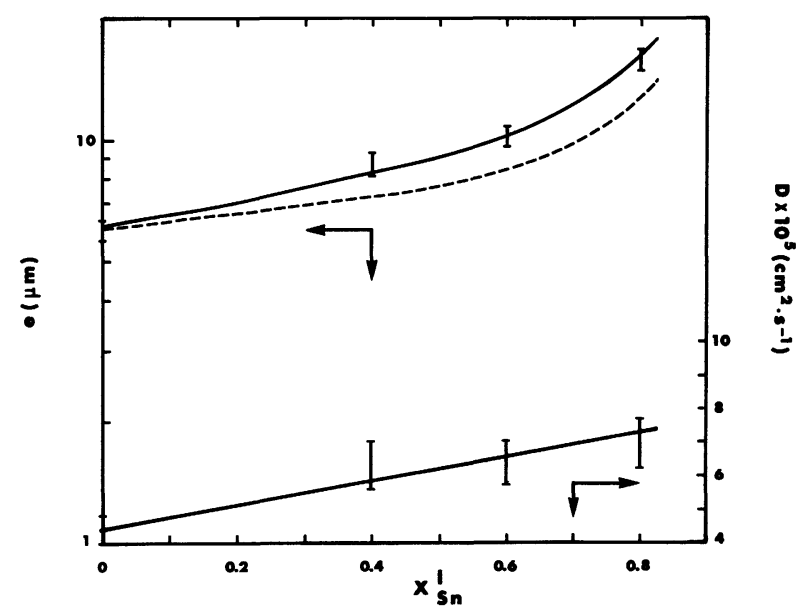

Fig. 4. - Experimental and calculated thickness of GaAs layer (upper curve) and estimated values of $D_{\mathrm{As}}$ in $\mathrm{Ga}-\mathrm{Sn}$ liquid alloy (lower curve). 
The system $\mathrm{Ga}-\mathrm{As}-\mathrm{Ge}$ has been experimentally studied in reference [11] at $1073 \mathrm{~K}$ in the Ga-rich corner up to $x_{\mathrm{Ge}}=0.4$. The method used was visualization. Our present measurements are made by the dissolution technique up to $x_{\mathrm{Ge}}=0.55$. The two sets of results are in very good agreement. The second system Ga-As-Sn has been previously determined by Panish [13] and more recently in reference 14. The liquidus slopes retained for the two systems are listed in table I. In the first step, we have calculated their influence on the growth rates. In the second step, the diffusion coefficient of As in the melt is adjusted to obtain a fit of the thickness of the deposited layer. So, the diffusion of As in liquid $\mathbf{G a}$ and in the liquid alloys $\mathrm{Ga}+\mathrm{Ge}$ and $\mathrm{Ga}+\mathrm{Sn}$ are estimated. The value of $D_{\mathrm{As}}$ in pure $\mathrm{Ga}$ has been previously determined at $1073 \mathrm{~K}$ [10]. Our present results confirm the former : $D_{\mathrm{As}}=4.4 \times 10^{-5} \mathrm{~cm}^{2} \mathrm{~s}^{-1}$.

For the Ga-As-Ge system, if we assume $D_{\mathrm{As}}$ as constant in the $\mathrm{Ga}+\mathrm{Ge}$ solvent, the thicknesses of layers versus $x_{\mathrm{Ge}}$ would be represented by the dotted line in the figure 3 . These theoretical results are smaller than the experimental values. The experimental thicknesses together with the liquidus slopes provide values of $D_{\mathrm{As}}$ for each melt composition. These data are given in the figure 3 and they will be represented for further calculation by the following straight-line $D_{\mathrm{As}}(\mathrm{Ga}+\mathrm{Ge})=4.4 \times 10^{-5}\left(1+1.1 x_{\mathrm{Ge}}\right) \mathrm{cm}^{2} \mathrm{~s}^{-1}$. Using this $D_{\mathrm{As}}$ expression we have calculated the thicknesses which are represented in the figure 3. So the theoretical and experimental results are in agreement.
Similarly, for the Ga-As-Sn system, if we assume $D_{\mathrm{As}}=4.4 \times 10^{-5} \mathrm{~cm}^{2} \mathrm{~s}^{-1}$ in the Ga-Sn solvent, the calculated thicknesses will be represented by the dotted line of figure 4. Using the liquidus slope and the experimental thicknesses, the values of $D_{\mathrm{As}}$ in the melt $\mathrm{Ga}+\mathrm{Sn}$ are estimated and are fitted by the following expression :

$$
D_{\mathrm{As}}(\mathrm{Ga}+\mathrm{Sn})=4.4 \times 10^{-5}\left(1+0.82 x_{\mathrm{Sn}}\right) \mathrm{cm}^{2} \mathrm{~s}^{-1} \text {. }
$$

The theoretical thicknesses are represented in figure 4; they agree very well with the experimental results. We must note that for $x_{\mathrm{Sn}}=0.8$ the value of $m$ is not very low and thus our growth model fails if the actual crystallization path differs from the tie-line extension.

\section{Conclusion.}

The growth rate of GaAs from a ternary melt of the Ga-As-dopant type was studied. Firstly, a growth model based on liquid diffusion as the limiting mechanism has been detailed. Secondly, an adequate procedure was used to measure the influence of $\mathrm{Sn}$ and $\mathrm{Ge}$ on the layers thicknesses. It was found that Ge does not affect the growth rate whereas $\mathrm{Sn}$ increases it considerably. These effects are mainly due to the liquidus shape and very moderately due to a slight increase of As diffusion in the alloys. These diffusion estimates are not confirmed at this time by techniques giving direct measurements. However, our results are in accordance with the generally accepted idea that the diffusion coefficients in liquid metals have similar values.
[1] Small, M. B. and Barnes, J. F., J. Crystal Growth 5 (1969) 9.

[2] Rode, A. L., J. Crystal Growth 20 (1973) 13.

[3] HsieH, J. J., J. Crystal Growth 27 (1974) 49.

[4] Moon, R. L., J. Crystal Growth 27 (1974) 62.

[5] Toyoda, N., Mihara, M. and Hara, T., J. Appl. Phys. 47 (1976) 443.

[6] BRYSKIEWICZ, T., J. Crystal Growth 43 (1978) 101.

[7] Reynolds, C. L. Jr, Tamargo, M. C., Anthony, P. J. and ZiLko, J. L., J. Crystal Growth 57 (1982) 109.

[8] Carslaw, H. S. and Jaeger, J. C., Conduction of Heat in Solids (Oxford Univ. Press, London) 1959.
[9] Pawlik, D., Siemens Forsch. 7 (1978) 4.

[10] Dutartre, D., J. Crystal Growth (to be published).

[11] Dutartre, D., Gavand, M., MaYet, L., Laugier, A. and Ansara, I., J. Physique Colloq. 43 (1982) C5-39.

[12] Abrahams, M. S. and Binocchi, C. J., J. Appl. Phys. 36 (1965) 2855.

[13] Panish, M. B., J. Appl. Phys. 44 (1973) 2659.

[14] Dutartre, D., Thesis, Lyon (1983). 